\title{
Soybean (lbc3), Parasponia, and Trema Hemoglobin Gene Promoters Retain Symbiotic and Nonsymbiotic Specificity in Transgenic Casuarinaceae: Implications for Hemoglobin Gene Evolution and Root Nodule Symbioses
}

\author{
Claudine Franche, Diaga Diouf, Laurent Laplaze, Florence Auguy, Thierry Frutz, Maryannick Rio, \\ Emile Duhoux, and Didier Bogusz \\ Physiologie Cellulaire et Moléculaire des Arbres (ORSTOM/GeneTrop), 911 avenue Agropolis, BP 5045, \\ 34032 Montpellier cédex 1, France \\ Accepted 25 May 1998.
}

The purpose of this study was to compare the control of expression of legume and nonlegume hemoglobin genes. We used the Casuarina glauca and Allocasuarina verticillata transformation system to examine the properties of the soybean (lbc3), Parasponia andersonii, and Trema tomentosa hemoglobin gene promoters in actinorhizal plants. Expression of the hemoglobin promoters gus genes was examined by fluorometric and histochemical assays. The fluorometric assays in various organs showed that the soybean and $P$. andersonii promoters were most active in nodules whereas the $T$. tomentosa promoter gave a very high activity in roots. The histochemical study showed that GUS activity directed by the soybean and the $P$. andersonii gus chimeric genes appeared mainly confined to the infected cells of the $C$. glauca and $A$. verticillata nodules. The $T$. tomentosa hemoglobin promoter was primarily expressed in the root's cortex and vascular tissue. The results indicate that the soybean, $P$. andersonii, and $T$. tomentosa hemoglobin promoters retain their cell-specific expression in transgenic members of the Casuarinaceae, suggesting a close relationship between legume, Ulmaceae member, and actinorhizal hemoglobin genes. The conservation of the mechanism for nodule-specific expression of soybean, $P$. andersonii, and $C$. glauca and $A$. verticillata hemoglobin genes is discussed in view of recent molecular phylogenetic data that suggest a single origin for the predisposition to form root nodule symbioses.

Additional keywords: actinorhiza, Frankia, nitrogen fixation.

Plant hemoglobins were first identified and characterized in the nitrogen-fixing root nodules that develop through the symbiotic association of Rhizobia spp. bacteria with leguminous plants. More recently, hemoglobins have also been found in nodules of nonlegumes, such as Parasponia andersonii nodulated by Bradyrhizobium spp. (Appleby et al. 1983; Landsmann et al. 1986) and Casuarina glauca, an actinorhizal plant that undergoes symbiosis with the actinomycete Frankia (Fleming et al. 1987; Jacobsen-Lyon et al. 1995). The role of

Corresponding author: D. Bogusz; E-mail: bogusz@mpl.orstom.fr hemoglobin in symbiosis is to supply oxygen to the bacterial respiration chain while preserving the activity of the oxygenintolerant nitrogenase enzyme complex (Appleby 1984).

Besides the symbiotic hemoglobin genes that are expressed specifically in nitrogen-fixing nodules, a second type of hemoglobin gene has been isolated in nodulating and nonnodulating plants. A nonsymbiotic hemoglobin gene was first recorded in Trema tomentosa, a non-nodulating relative of $P$. andersonii (Bogusz et al. 1988). Since then, nonsymbiotic hemoglobin genes have been identified in cereals such as barley, wheat, maize, and rice (Taylor et al. 1994) and in Arabidopsis thaliana (Trevaskis et al. 1997). These genes are expressed in different tissues, such as roots, stems, and seeds. The presence of nonsymbiotic hemoglobin genes in symbiotic plants has also been reported in soybean (Andersson et al. 1996) and in the actinorhizal tree C. glauca (Christensen et al. 1991; Jacobsen-Lyon et al. 1995). In contrast to their symbiotic counterparts, the nonsymbiotic hemoglobin genes of soybean and $C$. glauca were expressed in various nonsymbiotic tissues and the level of expression in nodules was very low, compared with that of hemoglobin symbiotic genes (Andersson et al. 1996; Jacobsen-Lyon et al. 1995). P. andersonii possesses a single hemoglobin gene that shows expression in both nodules and non-nodulated roots, suggesting symbiotic and nonsymbiotic roles for $P$. andersonii hemoglobin (Landsmann et al. 1986, 1988; Bogusz et al. 1988). The function of these nonsymbiotic hemoglobins is still unknown. It has been suggested that hemoglobin could act as a sensor of oxygen tension or as an oxygen carrier (Appleby et al. 1988).

The regulation of both symbiotic and nonsymbiotic hemoglobin gene expression has been studied with transgenic legumes. An examination of the expression of the chimeric hemoglobin promoter-reporter gene has shown that organspecific expression is mediated by cis-acting elements (Stougaard et al. 1987, 1990; Szabados et al. 1990; Bogusz et al. 1990; Jacobsen-Lyon et al. 1995; Andersson et al. 1997). Furthermore, the study of the expression of various hemoglobin promoters in transgenic legume has contributed to better understanding of the origin of hemoglobin genes in plants (Appleby et al. 1988; Appleby 1992). 
In our laboratory, we recently developed genetic transformation techniques for two actinorhizal trees in the Casuarinaceae family, C. glauca (Diouf et al. 1995) and Allocasuarina verticillata (Franche et al. 1997). To further investigate the evolution of plant hemoglobins, we introduced into $C$. glauca and $A$. verticillata chimeric genes consisting of the promoter region from the soybean $c 3(l b c 3)$, the $P$. andersonii, and the T. tomentosa hemoglobin genes linked to the coding region of the reporter gene gus (uidA) encoding $\beta$-glucuronidase (GUS).

We found that in transgenic nodules of $C$. glauca and $A$. verticillata, the soybean and $P$. andersonii hemoglobin promoters direct expression of the gus gene in Frankia-infected cells, thus indicating a conservation of cell-specific expression in the actinorhizal plants. We have also shown that the expression of the $T$. tomentosa hemoglobin gene promoter in $C$. glauca and $A$. verticillata nonsymbiotic tissue is essentially root specific. The different patterns of expression were compared with those of the endogenous soybean, $P$. andersonii, and $T$. tomentosa hemoglobin genes, and with the expression previously reported in the heterologous transgenic legume, Lotus corniculatus.

\section{RESULTS}

Quantitative GUS activity in roots, nodules, and shoots (stem/leaves) of transgenic $A$. verticillata.

GUS activity controlled by the hemoglobin promoters was determined in extracts of shoots (stems/leaves), roots, and nodules of transgenic $A$. verticillata. Since $C$. glauca and $A$. verticillata are characterized by distinctive foliage consisting of deciduous, long, needlelike, articulate branchlets with reduced, scalelike leaves organized in whorls, the GUS activity measured in shoots represents the activity in stems and leaves. These experiments were carried out on two to five plants regenerated from each of 20 independently transformed calli. Table 1 summarizes the results of GUS activity in transgenic A. verticillata plants. The variability observed between independent transformants can be explained by differences in transgene copy number, methylation, and/or integration site (for review see Finnegan and McElroy 1996). As expected, the control plants carrying cauliflower mosaic virus (CaMV) e35S-gus showed GUS activity throughout the transgenic $A$. verticillata plants (Franche et al. 1997). In untransformed

Table 1. $\beta$-Glucuronidase (GUS) activity in different organs of transgenic Allocasuarina verticillata ${ }^{\mathrm{a}}$

\begin{tabular}{lccr}
\hline Construct $^{\mathbf{b}}$ & Shoot $^{\mathbf{c}}$ & Root & Nodule \\
\hline lbc3-gus & $0.2 \pm 0.3$ & $0.43 \pm 0.5$ & $1.08 \pm 0.7$ \\
$P$-gus & $1.3 \pm 0.3$ & $0.7 \pm 0.2$ & $12.7 \pm 0.2$ \\
T-gus & $0.97 \pm 0.4$ & $456.5 \pm 35$ & $0.3 \pm 0.3$ \\
e35S-gus & $214.7 \pm 29$ & $293.8 \pm 52$ & $1.6 \pm 0.2$ \\
Untransformed & $0.26 \pm 0.2$ & $0.15 \pm 0.07$ & $0.01 \pm 0.0$ \\
\hline
\end{tabular}

${ }^{a}$ GUS-specific activity was determined by fluorometric assays with tissue homogenates from at least 20 independent transgenic plants. Activity is expressed as $\mu \mathrm{mol}$ of MU (4-methyl umbelliferone) per min per $\mathrm{mg}$ of protein.

b $l b c 3$, soybean hemoglobin gene promoter; P, Parasponia andersonii hemoglobin gene promoter; $T$, Trema tomentosa hemoglobin gene promoter; $e 35 S$, cauliflower mosaic virus (CaMV) promoter containing a duplication of the $\mathrm{B}$ domain of the $35 \mathrm{~S}$ promoter.

${ }^{c}$ Shoot tissue consists of reduced leaves around the stem segment. nodules, the GUS values were lower than in shoots, suggesting that the high content of phenolic compounds in A. verticillata nodules could reduce endogenous GUS activity (Serres et al. 1997).

The soybean lbc3-gus construct was not significantly expressed in the aerial part of the plants or in the non-nodulated roots. Although low GUS activity was observed in transformed $l b c 3$-gus nodules, the values obtained were up to 100 times higher than those observed in nontransformed nodules. A similar pattern of GUS activity was observed in L. corniculatus transformed with the same lbc3-gus construct (Lauridsen et al. 1993).

The gus expression produced by the $P$. andersonii hemoglobin promoter in shoots and roots was slightly above the background of untransformed extracts. High reporter GUS activity was observed in nodules; the level of expression was about 10 times higher than the level detected with the lbc3-gus construct (Table 1).

The T. tomentosa gus construct gave a low level of GUS activity in shoots, whereas a high expression was observed in roots. In nodules, the measured reporter gene activity was up to 30 times higher than the level detected in nontransformed nodules (Table 1).

\section{Expression of the soybean $(l b c 3)$ and $P$. andersonii hemoglobin promoters in transgenic $C$. glauca and $A$. verticillata nodules.}

The GUS activity was further studied by examining sections of C. glauca and A. verticillata nodules. Similar results were obtained in the two systems.

In any given lobe of $C$. glauca or A. verticillata, Frankia is restricted to the cortical cells. The way Frankia invades cortical parenchyma cells growing acropetally toward the nodule lobe meristem creates a developmental gradient. Different zones have been characterized by both morphological and gene expression studies (Angulo Carmona 1974; Ribeiro et al. 1995; Gherbi et al. 1997), e.g., the apical meristematic zone at the apex (zone I), the infection zone (zone II) where Frankia infects some of the new cells derived from the meristem, the fixation zone (zone III) where active nitrogen fixation takes place, and the senescence zone (zone IV).

As shown in Figure 1A, the longitudinal section of mature A. verticillata nodules revealed that the lbc3-gus gene was active throughout the cortical cells that correspond to the Frankia-containing cells. Expression was at its highest in the early fixation zone III immediately adjacent to infection zone II. Although the $C$. glauca and A. verticillata nodule lobe has an indeterminate growth pattern, like indeterminate type legume nodules, the so-called interzone II-III (Vasse et al, 1990) between zone II and III has not been found. Toward the senescence zone IV, lbc3-gus expression progressively decreased. No activity was seen in the periderm, vascular bundle, or meristematic zone (Fig. 1A). The cell-specific expression of the lbc3-gus construct was studied in thin, transversal sections of transgenic nodules (Fig. 1B). GUS activity was localized in large Frankia-infected cells. No activity was seen in the uninfected cells, periderm, or vascular parenchyma (Fig. 1B). When transgenic $l b c 3$ roots were stained for GUS activity, expression was not detected in lateral or primary roots (Fig. $2 \mathrm{~A}$ ) or in aerial parts (not shown). We concluded that, in mature C. glauca and A. verticillata nodules, the lbc3-gus con- 
struct was expressed exclusively in Frankia-infected cells. This is similar to the localization of the endogenous $C$. glauca symbiotic hemoglobin mRNA (Gherbi et al. 1997) and protein (Goodchild and Miller 1997).

In a mature $A$. verticillata nodule lobe, the chimeric $P$. andersonii gene was highly active in the cortical, Frankiainfected part (Fig. 1C), and, occasionally, weaker GUS staining was observed in the vascular bundle (not shown). Analyses at high magnifications under the more sensitive dark-field conditions showed that expression was most prominent in mature Frankia-infected cells (Fig.1D). GUS activity was also detected in Frankia-noninfected cells of the fixation zone and in the vascular bundle (Fig. 1D).

\section{Expression of the T. tomentosa hemoglobin promoter in transgenic $C$. glauca and $A$. verticillata nodules.}

As already mentioned for the $l b c 3$ and $P$. andersonii-gus constructs, no difference in expression was observed between nodules developed on transgenic roots of $C$. glauca and $A$. verticillata. The $T$. tomentosa-gus expression was most frequently seen in the vascular bundle zone of the nodule lobe (Fig. 1F). A transverse section of the transgenic nodule lobe revealed a blue-stained vascular cylinder (not shown), and the central metaxylem appeared to be free of any blue precipitate (not shown). GUS activity was occasionally seen in a few Frankia-infected cells in the fixation zone without any expression in the vascular tissue of the nodule lobe (Fig. 1E).

\section{Expression of the $P$. andersonii and $T$. tomentosa promoters in transgenic $C$. glauca and $A$. verticillata nonsymbiotic tissues.}

The distribution of gus expression was determined histochemically in transgenic, non-nodulated $C$. glauca (not shown) and A. verticillata roots (Fig. 2), and in A. verticillata transgenic shoots (not shown). The gus expression observed in roots was comparable in the two transgenic plants.

The $P$. andersonii-gus construct was expressed in root caps of the primary roots (Fig. 2C); staining was not seen in other parts of the primary root nor in lateral roots (Fig. 2B). A histochemical analysis of thin, longitudinal sections of the primary root tip showed staining in the outer part of the root cap (Fig. 2D). In P. andersonii, the endogenous hemoglobin gene is expressed at low level in roots (Bogusz et al. 1988; Landsmann et al. 1988).

The T. tomentosa-gus plants showed high levels of GUS activity in the primary roots (Fig. 2E). Staining was observed in the primary root tips but was not detected in the elongation region (Fig. 2F); newly emerging lateral roots expressed GUS activity in the region near the parent primary root (Fig. 2E). No staining was detected in the tip and the elongation region of the lateral roots containing the T. tomentosa-gus construct (Fig. 2E). The expression of the T. tomentosa hemoglobin gene was also observed in T. tomentosa roots (Bogusz et al. 1988). No staining was detected in transgenic A. verticillata shoots containing the soybean lbc3-gus construct (not shown). Very diffuse staining was detected occasionally in leaves with the T. tomentosa-gus and the $P$. andersonii-gus construct that was located at the internods (not shown). In T. tomentosa and $P$. andersonii, hemoglobin transcripts were not detected by Northern (RNA) blot analysis in leaves (Landsmann et al. 1988; Bogusz et al. 1988).

\section{DISCUSSION}

The soybean $l b c 35^{\prime}$-upstream region has been extensively studied (Stougaard et al. 1987, 1990). A deletion analysis of the $l b c 3$ promoter identified cis-acting regulatory elements (OSE: organ-specific element) that determine high-level, nodule-specific expression. It has been suggested that two motifs, AAGAT and CTCTTC, that are present in the OSE of all leghemoglobin genes and in the promoters of other legume nodule-specific genes, could constitute the regulatory sequences required for the nodule-specific expression (Sandal et al. 1987; Stougaard et al. 1987). In transgenic L. corniculatus, correct developmental regulation of the $l b c 3$ promoter is maintained, suggesting the conservation of regulatory signals between different legume species. Also, Jacobsen-Lyon et al. (1995) have shown that the two motifs were also present in the promoter of the nonlegume $C$. glauca symbiotic hemoglobin gene, and that these elements were responsible for the nodule-specific expression in transgenic $L$. corniculatus plants. Our data indicate that the $l b c 3$ promoter retains its cellspecific expression in transgenic actinorhiza. Altogether, heterologous expression analysis of the $l b c 3$-gus construct indicated a conservation of the mechanisms that determine high levels of endophyte-infected cell expression in mature legume and actinorhizal nodules.

The pattern of expression of the $P$. andersonii-gus chimeric gene in transgenic $C$. glauca and $A$. verticillata nodules is comparable to that of the single $P$. andersonii hemoglobin gene in the $P$. andersonii nodule, which is expressed in both Rhizobium-infected cells and in uninfected cells (Trinick et al. 1989). Thus, it appears that $P$. andersonii, the only nonlegume nodulated by a Rhizobium strain, and actinorhizal plants have similar regulatory mechanisms that control cell-specific expression in nodules. Surprisingly, Andersson et al. (1997) found that the $P$. andersonii hemoglobin promoter directed the expression of the gus gene at a high level in uninfected cells of mature transgenic $L$. corniculatus nodules, whereas a low level of GUS staining was detected in Rhizobium-infected cells. This indicates that, unlike the $l b c 3$ promoter, the $P$. andersonii hemoglobin promoter does not retain its cell-specific expression in transgenic legume nodules. It is interesting to note that both $P$. andersonii and $C$. glauca nodules are developmentally and structurally similar to lateral roots (Trinick 1979). Whereas legume nodules arise from the root cortex and exhibit peripheral vascular bundles, nonlegume nodules originate from pericycle cells, and their final structure resembles lateral roots with a single central vascular bundle. Furthermore, molecular phylogeny suggests that all root-nodule, nitrogen-fixing symbioses were contained in the same clade (Soltis et al. 1995). In this analysis, legumes are grouped in a unique subclade, while representatives of the Ulmaceae family (P. andersonii/Rhizobium symbiosis) are found in another subclade together with intercellularly infected actinorhizal plants; the Casuarinaceae family belongs to a third subclade with intracellularly infected actinorhizal plants. Therefore, molecular phylogenetic data indicate that, although $P$. andersonii and legumes share the same symbiont, $P$. andersonii is not closer to legumes than to $C$. glauca and A. verticillata. Thus, it might be possible that legume and nonlegume symbioses have diverged to the point that nodule transcription factors of L. corniculatus do not recognize nodule-specific 

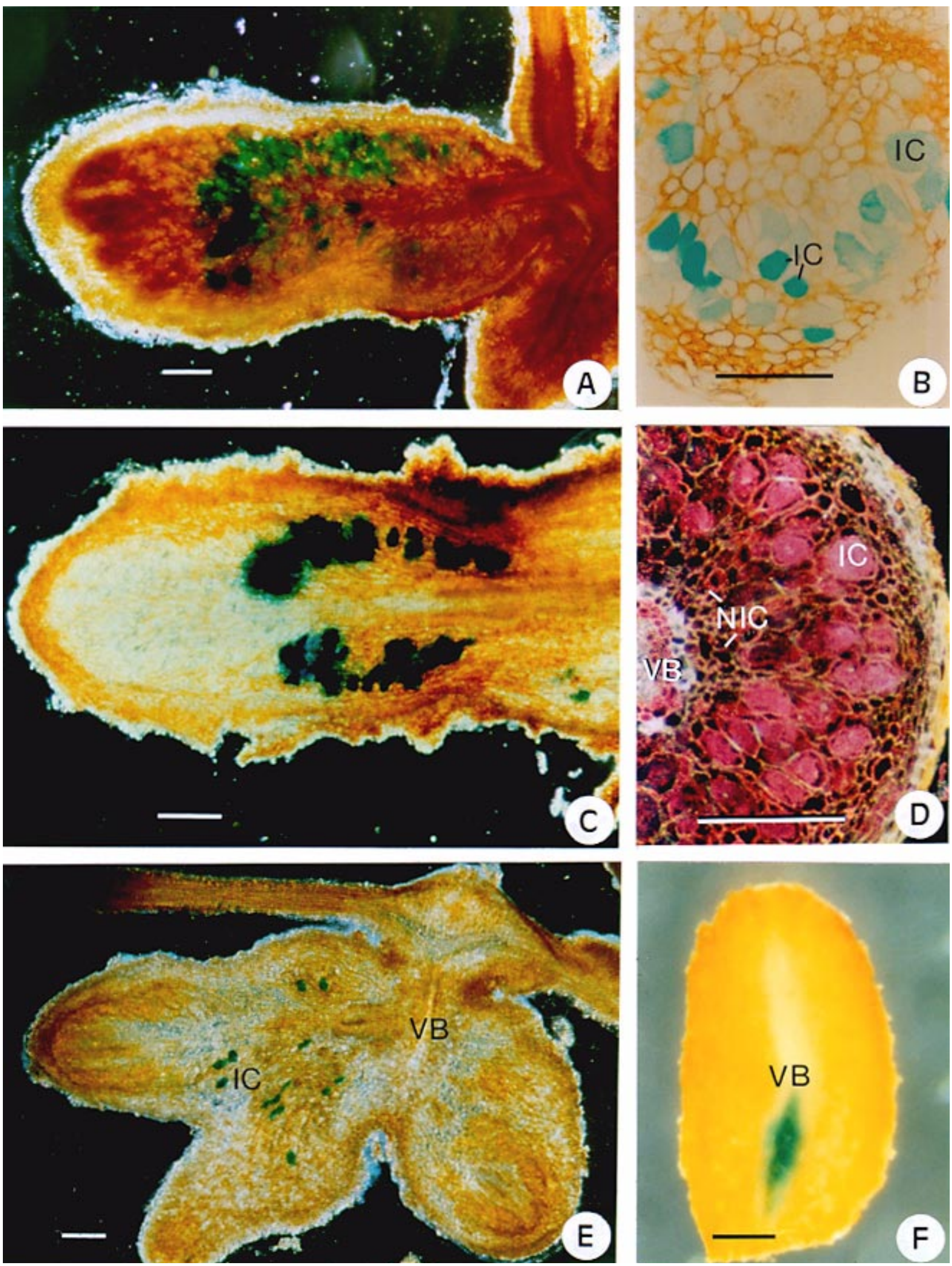
Fig. 1. A-F, Histochemical analysis of $\beta$-glucuronidase (GUS) activity of the chimeric plant hemoglobin gus-gene (A, B) lbc3, (C, D) Parasponia andersonii, and (E, F) Trema tomentosa of transgenic Allocasuarina verticillata nodules. A, B, C, E, and F, Bright field micrographs. D, A dark-field micrograph in which GUS staining is visible as pink color. A, Longitudinal section ( $45 \mu \mathrm{m}$ thick) of mature nodule lobe. B, Detail of 3- $\mu \mathrm{m}-$ thick cross section around vascular bundle. C, Longitudinal section (45 $\mu \mathrm{m}$ thick) of mature nodule lobe. D, Detail of 3- $\mu \mathrm{m}$-thick cross section in region of Frankiainfected cells. E Longitudinal section ( $45 \mu \mathrm{m}$ thick) of three nodule lobes. F, Longitudinal hand-cut section of a nodule lobe. IC, Frankia-infected cells; NIC, noninfected cells; VB, vascular bundle. Bars $=200 \mu \mathrm{m}$.
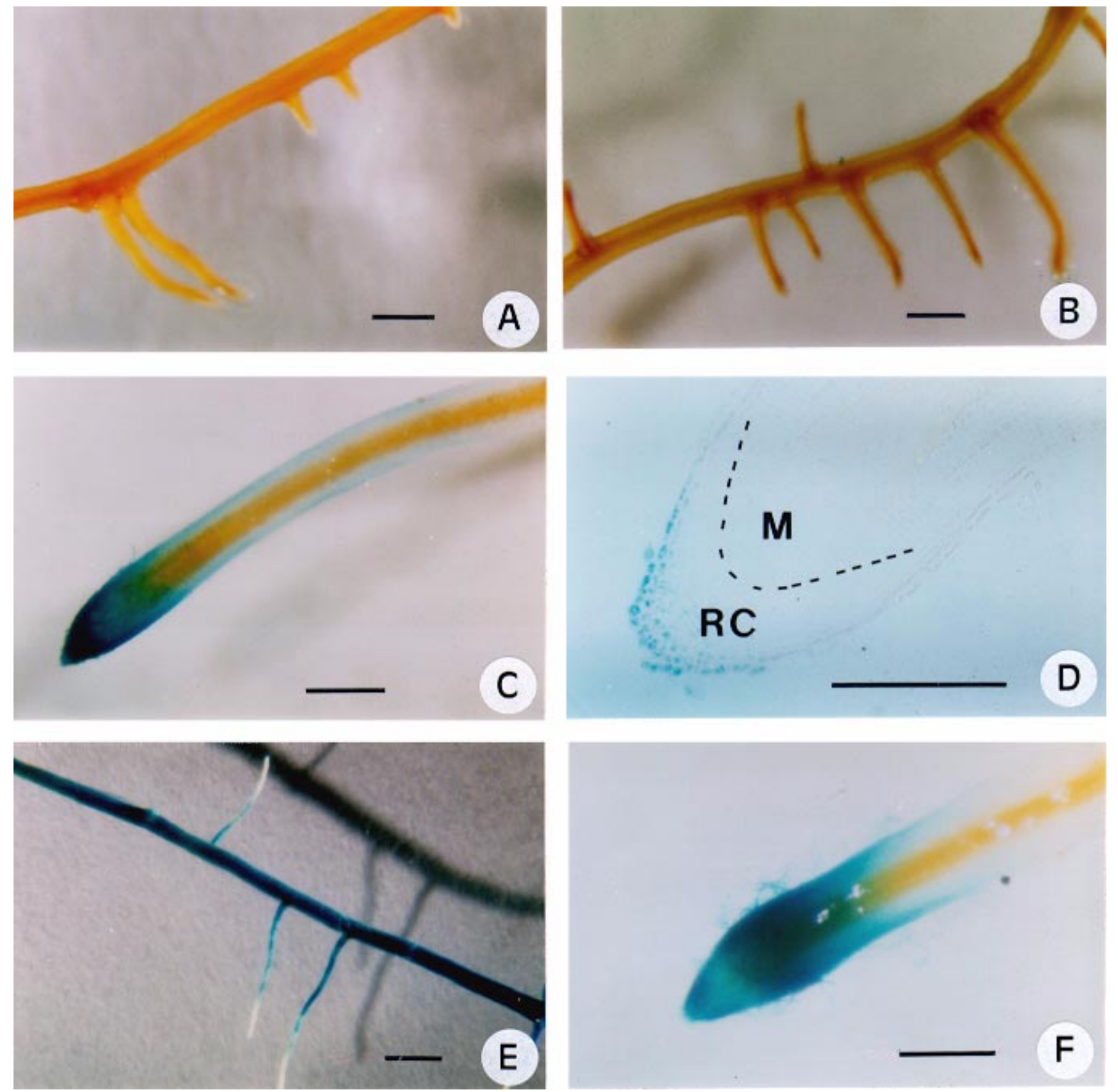

Fig. 2. A-F, Histochemical analysis of $\beta$-glucuronidase (GUS) activity of the chimeric plant hemoglobin gus-gene (A) lbc3, (B-D) Parasponia andersonii, and (E, F) Trema tomentosa of transgenic Allocasuarina verticillata roots. A, B, Root fragments. C, Fragment of primary root tip section. D, Longitudinal section ( $3 \mu \mathrm{m}$ thick) of primary root tip. E, Root fragment showing intense GUS staining in primary root and proximal region of secondary root. F, Root tip fragment of primary root showing intense staining in meristematic region. M, meristem; RC, root cap. Bars $=(\mathbf{A}, \mathbf{B}, \mathbf{C}, \mathbf{F}) 400 \mu \mathrm{m},(\mathbf{D})$ $200 \mu \mathrm{m}$, (E) $500 \mu \mathrm{m}$. 
DNA motifs of $P$. andersonii symbiotic genes. However, as reported previously, Jacobsen-Lyon et al. (1995) found that the symbiotic cashb-sym C. glauca hemoglobin promoter retained its symbiont-infected, cell-specific expression in transgenic legumes. The conservation of the cell-specific expression of the $P$. andersonii hemoglobin promoter in $C$. glauca and $A$. verticillata nodules, the absence of cell-specific expression of the same promoter in L. corniculatus, together with the correct pattern of expression of the cashb-syml and $l b c 3$ promoters in transgenic $L$. corniculatus, suggest that the symbiotic function of the $P$. andersonii hemoglobin gene is more closely related to $C$. glauca and $A$. verticillata symbiotic genes than to the legume's. The behavior of the $P$. andersonii hemoglobin promoter in transgenic $C$. glauca and $A$. verticillata and L. corniculatus nodules could also be correlated to the unique feature of this hemoglobin gene with both a symbiotic and a nonsymbiotic function.

We found that the $T$. tomentosa-gus construct was expressed in transgenic $C$. glauca and $A$. verticillata nodules and that the cell-type specificity varied among individual transgenic nodules. Two different cell-type expressions were observed. Indeed, in most transgenic nodules, GUS staining was specifically seen in cells of the vascular bundle (Fig. $1 F)$; in a few nodules there was GUS staining of the Frankia-infected cells (Fig. 1E). This suggests that, although some symbiotic expression was retained in $C$. glauca and $A$. verticillata nodules, the symbiotic regulatory sequences within the $T$. tomentosa promoter were imperfectly recognized by the transcription factors of the $C$. glauca and A. verticillata nodules that interact with the cis regulatory elements. Altogether, the sequence data analysis (Bogusz et al. 1988), our results, and previous reports from both Bogusz et al. (1990) and Andersson et al. (1997) suggest that the $T$. tomentosa hemoglobin promoter possesses all the basic elements for symbiotic regulation but that evolutionary change has not led to a precise control of cell expression within the nodule. As suggested by Andersson et al. (1997), it is possible that $T$. tomentosa might have been a nodulating species and lost its ability to form nodules.

The pattern of expression of the $P$. andersonii-gus chimeric gene in transgenic $C$. glauca and $A$. verticillata roots differs from that reported in transgenic L. corniculatus roots. Bogusz et al. (1990) detected a low level of staining in the vascular bundle whereas Andersson et al. (1997) did not observe any GUS activity. The root cap consists of living parenchyma cells derived from the apical meristems. These cells secrete a mucilage that coats root tips growing in the soil (Rougier 1981). It has been suggested that the role of the $P$. andersonii hemoglobin in roots could be to facilitate oxygen diffusion in rapidly respiring cells (Appleby et al. 1988); thus, the expression of the $P$. andersonii-gus construct may be correlated with the high metabolic activity of the root cap cells.

In transgenic L. corniculatus roots, Andersson et al. (1997) reported that the expression of the T. tomentosa-gus construct was occasionally observed in the root caps or root meristem initial cells.

As already suggested above for the $P$. andersonii promoter, the $T$. tomentosa hemoglobin promoter seems to be more accurately recognized by $C$. glauca and $A$. verticillata than by legume transcription factors. Since $T$. tomentosa is a close relative of $P$. andersonii, this finding is in agreement with our previous suggestion that the Ulmaceae hemoglobin genes are more closely related to $C$. glauca and $A$. verticillata genes than to leghemoglobin genes.

On the basis of their protein sequence analysis, Trevaskis et al. (1997) reported that two classes of hemoglobin are present in plants. The nonsymbiotic $C$. glauca, legume, and $P$. andersonii and $T$. tomentosa hemoglobins belong to class 1 , whereas the symbiotic $C$. glauca and legume hemoglobins belong to class 2 .

Our results showed that symbiotic and nonsymbiotic functions of the $P$. andersonii and $T$. tomentosa hemoglobin gene promoters were maintained in transgenic $C$. glauca and A. verticillata nodules, whereas Andersson et al. (1997) reported that the same promoters were not correctly recognized in transgenic L. corniculatus. This suggests that $P$. andersonii and $T$. tomentosa hemoglobin genes share common regulatory mechanisms with symbiotic and nonsymbiotic $C$. glauca and $A$. verticillata hemoglobin genes. Thus, even if $P$. andersonii, $T$. tomentosa, and symbiotic Casuarina hemoglobin belong to different classes, the corresponding genes have acquired common regulatory mechanisms through evolutionary convergence.

We have also shown that the symbiotic and nonsymbiotic functions of the $P$. andersonii and the $T$. tomentosa hemoglobin genes are more specifically recognized in transgenic $C$. glauca and A. verticillata than in legume, although both legume and $P$. andersonii are nodulated by Rhizobium. This suggests that symbiotic microorganisms are not involved in the nodule-infected cell expression of hemoglobin genes and that the specializations of plant and endophyte symbiotic genes have evolved independently. As mentioned previously, Andersson et al. (1997) have determined the root and the nodulespecific DNA signals of the $P$. andersonii and $T$. tomentosa hemoglobin promoters in transgenic L. corniculatus; it would be interesting to make the same functional analysis in transgenic $C$. glauca and A. verticillata in order to establish whether the same DNA regulatory elements are recognized in legume and actinorhizal plants.

An increased number of nodule-specific and enhanced genes are being isolated in legumes and actinorhizal plants (Mylona et al. 1995; Mullin and Dobritsa 1996; Franche et al. 1998). The prospect of introducing the promoters of these genes into heterologous symbiotic systems opens new avenues of study on the evolution of nodulation and symbiotic genes.

\section{MATERIALS AND METHODS}

\section{Plant materials.}

C. glauca seeds were kindly provided by H. H. El Lakani from the Desert Developmental Center (Cairo) and A. verticillata seeds collected in Australia were obtained from the Versepuy Company (Le Puy-en-Velay, France). For stable transformation, $C$. glauca and A. verticillata were propagated in tissue culture under sterile conditions at $26^{\circ} \mathrm{C}$ with a $16-\mathrm{h}$ photoperiod (Diouf et al. 1995; Franche et al. 1997).

\section{Bacterial strains and plasmids.}

The Agrobacterium tumefaciens strain C58C1(GV2260) (Vancanneyt et al. 1990) and A. rhizogenes A4RS (Jouanin et al. 1986) were used for transformation experiments. The soybean lbc3-gus-NOS chimeric gene plasmid, kindly provided 
by K. Marker (Lauridsen et al. 1993), was digested with HindIII and inserted into the HindIII site of the binary vector pBin19 (Bevan 1984). The P. andersonii and T. tomentosa hemoglobin promoter gus-NOS constructs in the binary vector pGA470 were kindly provided by E. Dennis (Bogusz et al. 1990). CaMV 35S-gus gene fusion (pBI121) (Jefferson et al. 1987) was used as a control. Binary vectors were introduced in A. tumefaciens and A. rhizogenes by triparental mating (Koncz and Schell 1986) and individual colonies were tested by Southern analysis for the presence of the construct.

\section{Plant transformation and nodulation by Frankia.}

Composite C. glauca plants, consisting of transgenic roots on untransformed shoots, were generated with engineered $A$. rhizogenes as described previously (Diouf et al. 1995). Transgenic $A$. verticillata was recovered through the transformation of mature zygotic embryos by engineered A. tumefaciens, as described previously (Franche et al. 1997). Transformed plants were characterized for stable integration by Southern and polymerase chain reaction analyses (Franche et al. 1997). Transgenic $C$. glauca and A. verticillata were grown in glass tubes containing a nutrient solution (Hoagland) or were transferred to soil in a glass house. Transgenic $C$. glauca was inoculated by the Frankia strain Thr (Girgis et al. 1990) and A. verticillata by Allo2 (Girgis and Schwencke 1993).

\section{Fluorometric assay for GUS activity.}

Total protein (5 to $10 \mu \mathrm{g}$ ) from shoots (stem/leaves), roots, and nodules of transgenic and nontransformed control plants was used in the assay. The kinetic analysis of the GUS activity was performed with $1 \mathrm{mM}$ methyl umbelliferyl glucuronide (MUG) as a substrate, as described by Jefferson et al. (1987). GUS activities were expressed as $\mu$ mol of 4-methyl umbelliferone (4-MU) produced per mg of protein. The average activity for each construct was determined following the analysis of an average of 20 independent transformed plants.

\section{Histochemical localization of GUS activity.}

GUS activity was detected in small fragments of root and nodule samples essentially as described by Jefferson et al. (1987). Nontransformed plants were used as negative controls. Nodules that exhibited four to six lobes were analyzed.

Samples were sliced into $45-\mu \mathrm{m}$-thick sections (VT 1000E vibratome; Leica, Heerbrugg, Switzerland). Tissue sections were viewed by a Leitz DMRB light microscope with brightand dark-field optics. Alternatively, stained samples were post-fixed for $24 \mathrm{~h}$ in ethanol, acetic acid, formaldehyde (17, $2,1)$ then dehydrated through graded ethanol solutions and embedded in resin (Histo Technik 7100; Labonord, Villeneuve d'Arcq, France). Two- to 3- $\mu$ m-thick sections (Leica GRM 2055 microtome) were mounted on slides before observation by light microscopy.

\section{ACKNOWLEDGMENTS}

We would like to thank K. Pawlowski (Albrecht-V-Haller-Institut, Göttingen, Germany) for critical reading of the manuscript, S. Svistoonoff for help with cytological work, and L. Padiou for fluorometric analysis. The work was supported by ORSTOM (Institut Français pour le Développement en Coopération), by CIRAD (Centre de Coopération Internationale en Recherche Agronomique), and by European contract ERTBTS 3*-CT940978.

\section{LITERATURE CITED}

Andersson, C. R., Jensen, E. O., Llewellyn, D. J., Dennis, E. S., and Peacock, W. J. 1996. A new hemoglobin gene from soybean: A role for hemoglobin in all plants. Proc. Natl. Acad. Sci. USA 93:56825687.

Andersson, C. R., Llewellyn, D. J., Peacock, W. J., and Dennis, E. S. 1997. Cell-specific expression of the promoters of two nonlegume hemoglobin genes in transgenic legume, Lotus corniculatus. Plant Physiol. 113:45-57.

Angulo Carmona, A. F. 1974. La formation des nodules fixateurs d'azote chez Alnus glutinosa (L.). Acta Bot. Neerl. 23:257-303.

Appleby, C. A. 1984. Leghemoglobin and Rhizobium respiration. Ann. Rev. Plant Physiol. 35:443-478.

Appleby, C. A. 1992. The origin and functions of haemoglobin in plants. Sci. Progress (Oxford) 76:365-398.

Appleby, C. A., Bogusz, D., Dennis, E. S., and Peacock, W. J. 1988. A role for haemoglobin in all plant roots? Plant Cell Environ. 11:359367.

Appleby, C. A., Tjepkema, J. D., and Trinick, M. J. 1983. Hemoglobin in a nonleguminous plant, Parasponia. Possible genetic origin and function in nitrogen fixation. Science 220:951-953.

Bevan, M. 1984. Binary Agrobacterium vectors for transformation. Nucleic Acids Res. 12:8711-8721.

Bogusz, D., Appleby, C. A., Landsmann, J., Dennis, E. S., Trinick, M. J., and Peacock, W. J. 1988. Functioning hemoglobin genes in a nonnodulating plant. Nature 331:178-180.

Bogusz, D., Llewellyn, D. J., Craig, S., Dennis, E. S., Appleby, C. A., and Peacock, W. J. 1990. Nonlegume hemoglobin genes retain organspecific expression in heterologous transgenic plants. Plant Cell 2: 633-641.

Christensen, T., Dennis, E. S., Peacock, W. J., Landsman, J., and Marcker, K. A. 1991. Hemoglobin genes in non-legumes: Cloning and characterization of a Casuarina glauca hemoglobin gene. Plant Mol. Biol. 16:339-344.

Diouf, D., Gherbi, H., Prin, Y., Franche, C., Duhoux, E., and Bogusz, D. 1995. Hairy root nodulation of Casuarina glauca: A system for the study of symbiotic gene expression in an actinorhizal tree. Mol. PlantMicrobe Interact. 8:532-537.

Finnegan, J., and McElroy, D. 1996. Transgene stability. Pages 170-186 in: Transgenic Plants: A Production System for Industrial and Pharmaceutical Proteins. M. R. L. Owen and J. Pen, eds. Wiley \& Sons, Chichester, UK.

Fleming, A. I., Wittenberg, J. B., Wittenberg, B. A., Dudman, W. F., and Appleby, C. A. 1987. The purification, characterization and ligandbinding kinetics of hemoglobins from root nodules of the nonleguminous Casuarina glauca-Frankia symbiosis. Biochem. Biophys. Acta 911:209-220.

Franche, C., Diouf, D., Le, Q. V., N'Diaye, A., Gherbi, H., Bogusz, D., Gobé, C., and Duhoux, E. 1997. Genetic transformation of the actinorhizal tree Allocasuarina verticillata by Agrobacterium tumefaciens. Plant J. 11:897-904.

Franche, C., Laplaze, L., Duhoux, E., and Bogusz, D. 1998. Actinorhizal symbioses: Recent advances in plant molecular and genetic transformation studies. Crit. Rev. Plant Sci. 17:1-28.

Gherbi, H., Duhoux, E., Franche, C., Pawlowski, K., Nassar, A., Berry, A., and Bogusz, D. 1997. Cloning of a full-length symbiotic hemoglobin cDNA and in situ localization of the corresponding mRNA in Casuarina glauca root nodule. Physiol. Plant. 99:608-616.

Girgis, M. G., Ishac, Y. Z., El-Haddad, M., Saleh., E. A., Diem, H. G., and Dommergues, Y. R. 1990. First report on isolation and culture of effective Casuarina-compatible strains of Frankia from Egypt. Pages 156-164 in: Int. Casuarina Worksh., 2nd. M. H. El-Lakany, J. W. Turnbull, and J. L. Brewbaker, eds.

Girgis, Z. M., and Schwencke, J. 1993. Differentiation of Frankia strains by their electrophoretic patterns of intracellular esterases and aminopeptidases. J. Gen. Microbiol. 139:2225-2232.

Goodchild, D. J., and Miller, C. 1997. Immunogold localisation of hemoglobin in Casuarina root nodules. Protoplasma 198:130-134.

Jacobsen-Lyon, K., Jensen, E. O., Jorgensen, J., Marker, K. A., Peacock, W. J., and Dennis, E. S. 1995. Symbiotic and non-symbiotic hemoglobin genes of Casuarina glauca. Plant Cell 7:213-222.

Jefferson, R. A., Kavanagh, T. A., and Bevan, M. W. 1987. GUS fusion: $\beta$-Glucuronidase as a sensitive and versatile gene fusion marker in 
higher plants. EMBO J. 6:3901-3907.

Jouanin, L., Tourneur, J., and Casse-Delbart, F. 1986. Restriction maps and homologies of three plasmids of Agrobacterium rhizogenes strain A4. Plasmid 6:124-134.

Koncz, C., and Schell, J. 1986. The promoter of TL-DNA gene 5 controls the tissue-specific expression of chimeric genes carried by a novel type of Agrobacterium binary vector. Mol. Gen. Genet. 204: 383-396.

Landsmann, J., Dennis, E. S., Higgins, T. J., Appleby, C. A., Kortt, A. A., and Peacock, W. J. 1986. Common evolutionary origin of legume and non-legume plant haemoglobins. Nature 324:166-168.

Landsmann, J., Llewellyn, D., Dennis, E. S., and Peacock, W. J. 1988. Organ regulated expression of the Parasponia andersonii haemoglobin gene in transgenic tobacco plants. Mol. Gen. Genet. 214:68-73.

Lauridsen, P., Franssen, H., Stougaard, J., Bisseling, T., and Marker, K. A. 1993. Conserved regulation of the soybean early nodulin ENOD2 gene promoter in determinate and indeterminate transgenic root nodules. Plant J. 3:483-492.

Mullin, B. C., and Dobritsa, S. V. 1996. Molecular analysis of actinorhizal symbiotic systems: progress to date. Plant Soil 186:9-20.

Mylona, P., Pawlowski, K., and Bisseling, T. 1995. Symbiotic nitrogen fixation. Plant Cell 7:869-885.

Ribeiro, A., Akkermans, A. D. L., van Kammen, A., Bisseling, T., and Pawlowski, K. 1995. A nodule-specific gene encoding a subtilisin-like protease is expressed in early stages of actinorhizal nodule development. Plant Cell 7:785-794.

Rougier, M. 1981. Secretory activity of the root cap. Pages 542-574 in Encyclopedia of Plant Physiology, New Series, Vol. 13B, Plant Carbohydrates II. W. Tanner, and F. A. Loewus, eds. Springer-Verlag, Berlin.

Sandal, N. N., Bojsen, K., and Marker, K. A. 1987. A small family of nodule-specific genes from soybean. Nucleic Acids Res. 15:15071519.

Serres, B., McCown, B., and Zeldin, E. 1997. Detectable $\beta$-glucuronidase activity in transgenic cranberry is affected by endogenous inhibitors and plant development. Plant Cell Rep. 16:641-646.

Soltis, D. E., Soltis, P. S., Morgan, D. R., Swensen, S. M., Mullin, B. C.,
Dowd, J. M., and Martin, P. G. 1995. Chloroplast gene sequence data suggest a single origin of the predisposition for symbiotic nitrogen fixation in angiosperms. Proc. Natl. Acad. Sci. USA 92:2647-2651.

Stougaard, J., Jorgensen, J. E., Christensen, T., Kühle, A., and Marker, K. A. 1990. Interdependence and nodule specificity of cis-acting regulatory elements in the soybean leghemoglobin $l b c 3$ and N23 gene promoters. Mol. Gen. Genet. 220:353-360.

Stougaard, J., Sandal, N. N., Gron, A., Kuhle, A., and Marker, K. A 1987. $5^{\prime}$ analysis of the soybean leghemoglobin $l b c_{3}$ gene: Regulatory elements required for promoter activity and organ specificity. EMBO J. 6:3565-3569.

Szabados, L., Ratet, P., Grunenberg, B., and de Bruijn, R. J. 1990. Functional analysis of the Sesbania rostrata leghemoglobin glb3 gene 5'upstream region in transgenic Lotus corniculatus and Nicotiana tabacum plants. Plant Cell 2:973-986.

Taylor, E. R., Nie, X. Z., MacGregor, A. W., and Hill, R. D. 1994. A cereal haemoglobin gene is expressed in seed and root tissues under anaerobic conditions. Plant Mol. Biol. 24:853-862.

Trevaskis, B., Watts, R. A., Andersson, C. R., Llewellyn, D. J., Hargrove, M. S., Olson, J. S., Dennis, E. S., and Peacock, W. J. 1997. Two hemoglobin genes in Arabidopsis thaliana: The evolutionary origins of leghemoglobins. Proc. Natl. Acad. Sci. USA 94:1223012234.

Trinick, M. J. 1979. Structure of nitrogen-fixing nodules formed by Rhizobium on roots of Parasponia andersonii. Can. J. Bot. 25:565-578.

Trinick, M. J., Goodchild, D. J., and Miller, C. 1989. Localization of bacteria and hemoglobin in root nodules of Parasponia andersonii containing both Bradyrhizobium strains and Rhizobium leguminosarum biovar trifolii. Appl. Environ. Microbiol. 55:2046-2055.

Vancanneyt, G., Schmidt, R., O'Conner-Sanchez, A., Willmitzer, L., and Rocha-Sosa, M. 1990. Construction of an intron-containing marker gene: Splicing of the intron in transgenic plants and its use in monitoring early events in Agrobacterium mediated plant transformation. Mol. Gen. Genet. 220:245-250.

Vasse, J., de Billy, F., Camut, S., and Truchet, G. 1990. Correlation between ultrastructural differentiation of bacteroids and nitrogen fixation in alfalfa nodules. J. Bacteriol. 172:4295-4306. 